\title{
Assessment of the short-term success of a translocation of lesser short-tailed bats Mystacina tuberculata
}

\author{
Jay Ruffell, Stuart Parsons* \\ School of Biological Sciences, University of Auckland, Private Bag 92019, Auckland, New Zealand
}

\begin{abstract}
Translocation is a powerful tool that has been used in the conservation of a wide range of taxa. However, few translocations of bats have been attempted and we know of no successes. The few translocations which have been attempted have either failed due to dispersal from the release site or have not been monitored sufficiently to determine the cause of failure. We assessed the shortterm success of a translocation of lesser short-tailed bats Mystacina tuberculata by the New Zealand Department of Conservation, where 3 release methods were used to minimise dispersal or mortality: bats were juveniles, were maintained in captivity at the release site, and were provided with supplementary food and roosts following release. Success was assessed by determining if founders remained at the release site and maintained condition (weight). Recapture showed that at least 9 of the 20 bats remained at the release site $232 \mathrm{~d}$ after release. There was weak evidence that bats lost weight, although final weights were comparable to those of bats from a natural population. However, all bats captured 8 mo after release had damaged, infected ears and some were balding. The problem was treated but recurred, and bats were returned to captivity. Our results are the first to demonstrate that translocated bats can remain at their release site and survive. However, disease may be an issue in future translocations.
\end{abstract}

KEY WORDS: Lesser short-tailed bat - Mystacina tuberculata - New Zealand · Translocation · Relocation $\cdot$ Reintroduction $\cdot$ Soft release $\cdot$ Supplementary food $\cdot$ Disease

\section{INTRODUCTION}

Translocation is a powerful and increasingly popular conservation tool that has been used in the management of a wide range of taxa (IUCN 1998, Seddon et al. 2007), but unsuccessfully in the conservation of bats. Nearly 250 species of bat are threatened (IUCN 2006), many of which could benefit from translocation. For example, small geographic range is the major predictor of extinction risk in bats (Jones et al. 2003). Translocation could re-establish populations in suitable parts of their former range, and has been recommended for several species of range-restricted old-world fruit bats (Mickleburgh et al. 1992). Translocation has also been recommended for lesser short-tailed bats Mystacina tuberculata to establish populations on islands within the historic range of the species free from the introduced mammalian predators and competitors thought to have been a factor in their decline (Molloy 1995, Lloyd 2003a).

Previous translocations of bats have been attempted only rarely and without success. Either bats have dispersed from the release site or insufficient monitoring has been undertaken to identify the cause of failure. Tomich (1986) reported several failed translocations of Asiatic pipistrelles Pipistrellus javanicus and freetailed bats Tadarida brasiliensis to Hawaii in the late 19th century, but the causes of failure are unknown. Translocation of 200 Pipistrellus spp. to 2 sites within $50 \mathrm{~km}$ of their original roost in Scotland resulted in all bats returning to their source population (S. Swift pers. comm.). Fifty lesser short-tailed bats were translocated to Ulva Island, a pest-free (i.e. free from introduced mammalian species) island off the northern coast of Stewart Island in southern New Zealand. Unfortunately, none could be relocated following release and 
it is believed they dispersed off the island (B. D. Lloyd unpubl. data), although they may have died soon after release. Similarly, experiments testing the navigational ability of a number of bat species by translocating them outside their home ranges have shown that they frequently return to their source populations (Davis 1966, Gunier \& Elder 1971, Guilbert et al. 2007).

Following the failure of the previous lesser shorttailed bat translocation, 3 techniques were suggested to prevent dispersal or mortality following release (B. D. Lloyd unpubl. report). First, founders should be juveniles, which may prevent return to the source population if the transfer occurs prior to imprinting. This technique has been used in the translocation of a number of highly philopatric seabirds (Serventy et al. 1989, Gummer 2003). Unfortunately, very little is known about location imprinting by bats, but juveniles appear to home less frequently than adults (Davis 1966). Snit'ko (2007) suggested that bats in the southern Urals imprint on sites that provide sufficient food and suitable hibernacula, although no distinction was made between the behaviour of fidelity and the mechanism of imprinting. Second, founders should be kept at the release site prior to release to increase site fidelity and allow recovery from the stress of handling and transfer. Third, they should be provided with supplementary resources following release to remove pressure to find resources in an unfamiliar environment.

In April 2005, the New Zealand Department of Conservation (NZDOC) attempted a second translocation of short-tailed bats using the 3 techniques suggested. The purpose of this translocation was to secure a small, genetically distinct population (Lloyd 2003b) believed to be in decline by establishing a new colony in an area with suitable pest-free habitat. The aim of the present study was to assess the short-term success of this translocation by determining if founders remained at the release site and maintained weight following release. Bats remaining at the release site indicated success in overcoming any homing response, while maintenance of weight was used as a proxy measure of overall condition. Short-term success would establish a working release protocol for the translocation of short-tailed bats that could serve as a model for the translocation of other species of bat. Short-term failure may also be informative if identification of the causes allows refinement of the protocol so that future success can be achieved.

Mystacina tuberculata is the only surviving member of the endemic family Mystacinidae. It is a highly terrestrial species (Riskin et al. 2006) that forages on a variety of terrestrial, aerial and arboreal insects, as well as fruit, pollen and nectar (Arkins et al. 1999). Colonial roost sizes vary, with reported sizes ranging from 100 to >6000 ind. (Lloyd 2001, Sedgeley 2006).
The species was once widespread throughout New Zealand but is now classified as vulnerable by the IUCN.

\section{MATERIALS AND METHODS}

Study site. Lesser short-tailed bats were translocated to Kapiti Island $\left(40.10^{\circ} \mathrm{S}, 174.55^{\circ} \mathrm{E}\right)$, a 1965 ha pestfree nature reserve $5 \mathrm{~km}$ off the southwest coast of North Island, New Zealand (Campbell 2002). The island lies approximately $40 \mathrm{~km}$ west of the bats' source population in the Tararua Range. An assessment of the island's ability to support a short-tailed bat population suggested that it was suitable in terms of its climate, the absence of introduced mammalian predators and competitors, and the availability of suitable roosts, although its ability to provide sufficient food could not be reliably assessed (Ruffell et al. 2007, J. Ruffell unpubl. data). The endemic long-tailed bat Chalinolobus tuberculatus is present on the island (J. Ruffell pers. obs.) but is unlikely to compete with short-tailed bats due to little ecological overlap (Arkins et al. 1999, Sedgeley 2003). The size of the C. tuberculatus population is unknown.

It is uncertain whether short-tailed bats were ever present on Kapiti Island. While the release site is within the historic range of the species (IUCN 1998), historical distribution records for short-tailed bats are lacking. Populations of short-tailed bats occur on several other nearby offshore islands.

The translocation was implemented by the NZDOC independently of the present study, and is described in detail by Adams et al. (2005). Briefly, 25 pregnant female short-tailed bats were captured from a population in the Tararua Range in December 2004 and transferred to an aviary at a nearby captive-breeding facility (Adams et al. 2005). Females were supplied with mealworms Tenebrio molitor and honey-water ad libitum, with moths also provided periodically. Females gave birth to 24 juveniles (1 female died giving birth). Of the 24 juveniles, 1 died from a bite to the back of the neck, 1 was stillborn, and 2 died from unknown causes. The remaining 4 males and 16 females survived. By February 2005 these surviving juveniles were weaned and had begun to fly and feed on supplementary food. Juveniles were then transferred to an aviary on Kapiti Island, where they were kept until their release on 11 April 2005 and were fed the same diet as that provided at the captive-breeding facility (pre-release feeding regime). After 11 April, animals were able to leave (and subsequently re-enter) the aviary of their own accord via a $1 \mathrm{~m}$ high $\times 0.15 \mathrm{~m}$ wide opening. This opening had been pre-installed into the aviary specifically for this purpose and was blocked by a piece of 
wood prior to the animals' release. The aviary was left open so the bats could roost in the same manner as pre-release, and mealworms and honey-water were provided ad libitum inside the aviary daily for $55 \mathrm{~d}$ after release (daily feeding regime), then irregularly (every $3.2 \mathrm{~d} \pm 0.4 \mathrm{SE}$, irregular feeding regime) until $157 \mathrm{~d}$ after release, when feeding was stopped (no feeding regime).

Following release, juveniles were provided with supplementary roosts in the form of 5 roost boxes (wiped clean to remove signs of use, but not scent) nailed to trees in the immediate vicinity of the aviary. The boxes had all been previously housed within the aviary and used by the bats. Roost boxes were checked weekly for signs of bats or guano but were never used by the bats post-release.

We monitored the condition and number of bats on Kapiti Island during 3 study periods in the year following the release (2005): an $8 \mathrm{wk}$ period from April to June, a 5 wk period from August to September, and a $1 \mathrm{wk}$ period from November to December. Monitoring ceased in December because bats were returned to captivity (see 'Results').

We used 2 methods to establish a minimum number of bats that remained on the island. (1) An infrared video camera recorded time-lapse images of the aviary entrance from 11 April to 1 June and from 23 September to 1 October. We tracked the number of bats inside the aviary throughout the night by counting all entries and exits, with the starting number known from carrying over the final number from the previous night, or when equipment did not record, from counting bats roosting in the aviary during the day. The maximum number of bats in the aviary gave the lower limit of the number that remained on the island. (2) We recaptured bats after release by taking them from the aviary during the day and by harp trapping ca. $20 \mathrm{~m}$ from the aviary at night. For the first month we captured bats on only 2 occasions (on release day and 6 d later) to minimise the chance of them dispersing away from the aviary or off the island. On these occasions we fitted 3 bats ( 2 on release day and one $6 \mathrm{~d}$ later) with $0.7 \mathrm{~g}$ radio-transmitters (BD-2, Holohil Systems) so that telemetry could be used to relocate them if other methods failed. The steep terrain of the island prevented telemetry from being used to determine more in-depth movement patterns. No method exists for permanently marking short-tailed bats without harming them, but following release we found that we could mark them temporarily by shaving ca. $3 \times 5 \mathrm{~mm}$ patches of fur from different locations on the dorsal surface. These patches were visible throughout the study. After 1 mo post-release we caught bats from the aviary whenever there were $>3$ present, but no more than once per week. The number of individuals captured after release gave the minimum number of bats that stayed on the island.

We used body weight as a proxy for condition. Captured bats were sexed and weighed to $\pm 0.5 \mathrm{~g}$ using a 60 g micro-balance (20060, Pesola AG). Weight data were analysed using JMP 5.1 (SAS Institute). The total number of released bats were never captured on any one sampling night, and not all bats were marked. This meant that the weights of individual bats could not be tracked over the course of the study and we could not employ a repeated-measures analysis. Therefore, we pooled weights into one of 4 categories depending on the feeding regime in place at the time the measurement was taken: pre-release, daily feeding, irregular feeding and no feeding. Bat weights were normalised with a square transformation (Shapiro-Wilks test, $\mathrm{p}>$ 0.05) prior to 1-way ANOVA to test if weights differed among feeding regimes. Descriptive statistics are reported as back-transformed means $\pm \mathrm{SE}$ and $95 \% \mathrm{CI}$.

We also surveyed for evidence of reproduction as an indicator of population sustainability. However, this was not a criterion for success because short-tailed bats may not breed in their first year of life (Lloyd 2001). Females caught during the November to December period were checked for vaginal plugs that form soon after mating (Lloyd 2001) and for bare skin around the nipples that indicates lactation or post lactation (Racey 1988). Testes and epididymides are not visible when males are reproductive (Lloyd 2001), so reproductive assessment was restricted to females.

\section{RESULTS}

Infrared video equipment recorded the aviary entrance on 32 nights following release, constituting $397 \mathrm{~h}$ of recording. Ten bats were in the aviary simultaneously $3 \mathrm{~d}$ after release, the maximum found throughout the study period. We caught a total of 40 bats on 11 occasions following their release, constituting 9 ind. All 9 bats, 4 males and 5 females, were still alive $232 \mathrm{~d}$ after release. The 3 bats fitted with radiotransmitters were relocated and were among the final 9 bats caught at the end of the study.

Back-transformed mean weights $( \pm \mathrm{SE})$ of bats ranged from $15.6 \pm 2.5 \mathrm{~g}$ during irregular feeding to $14.7 \pm 3.4$ and $14.7 \pm 2.7 \mathrm{~g}$ during daily feeding and no feeding, respectively (Table 1). The mean weight recorded during the no feeding regime, the most distant (temporally) regime from the time of release, was $14.7 \mathrm{~g}, 0.2 \mathrm{~g}$ higher that the mean weight of 448 Mystacina tuberculata from the most genetically similar wild population for which data are available (Lloyd $2003 b, 2005)$. There was no significant difference in weights recorded amongst feeding regimes $\left(F_{3,65}=\right.$ 
Table 1. Mystacina tuberculata. Mean weights of bats grouped by feeding regime in place at the time of measurement. Values given are back-transformed means \pm 1 SE with $95 \%$ CI. Although each bat was weighed only once during each capture, some were weighed more than once within each feeding regime

\begin{tabular}{|lcc|}
\hline Feeding regime & $\mathrm{n}$ & $\begin{array}{c}\text { Mean } \pm \mathrm{SE} \\
(95 \% \mathrm{CI})\end{array}$ \\
\hline Pre-release & 26 & $15.4 \pm 3.5$ \\
& & $(14.5-16.1)$ \\
Daily feeding & 13 & $14.7 \pm 3.4$ \\
Irregular feeding & 15 & $(13.9-15.5)$ \\
& & $15.6 \pm 2.5$ \\
No feeding & 12 & $(15.2-16.0)$ \\
& & $(14.7 \pm 2.7$ \\
\end{tabular}

Enrofloxacin to kill parasites and treat bacterial infection, respectively. These treatments were carried out by NZDOC staff, and the present study ended at this stage. NZDOC staff re-released bats on the island on 22 February 2006 (L. Adams pers. comm.); however, the NZDOC decided to return them to captivity permanently in August when one of the island's rangers discovered that ear damage had recurred (J. McIntosh pers. comm.). A team of vets working with the NZDOC have been unable to resolve the causes of ear damage and balding (L. Adams pers. comm.).

\section{DISCUSSION}

The translocation was at first successful, with many bats remaining on the island and surviving following
1.24, p > 0.05). Comparison of $95 \% \mathrm{CI}$ indicated that the difference in weights between irregular feeding and no feeding bordered on significance, with weights lower during the latter. Caution should be used when interpreting these results; although each bat was weighed only once during each capture, some were weighed more than once within each feeding regime.

No female bats caught during the November to December study period ( $\mathrm{n}=$ 5) showed any signs of having copulated or lactated.

All 8 bats caught in the aviary on 29 November, $232 \mathrm{~d}$ after release, had scabbing over the distal end of their pinnae. In several animals this scabbing caked the top half of the ear (Fig. 1a), with severe swelling and reddening of the exposed skin below indicating infection. Two bats also had bald patches, one on the dorsal surface (Fig. 1b) and one around the groin. To allow further observation and treatment we blocked the aviary entrance and kept the bats captive in the same manner as prerelease. A ninth bat harp-trapped 2 nights later also had scabbing and was placed in the aviary. The mean weight of these 9 bats was $14.5 \mathrm{~g}$ (Table 1). These symptoms were not visible when bats were last captured on 2 October.

A vet inspected the bats on 3 December and, based on clinical signs, tentatively diagnosed the problem as a mite infestation. She prescribed an injection of Ivermectin and a series of injections of
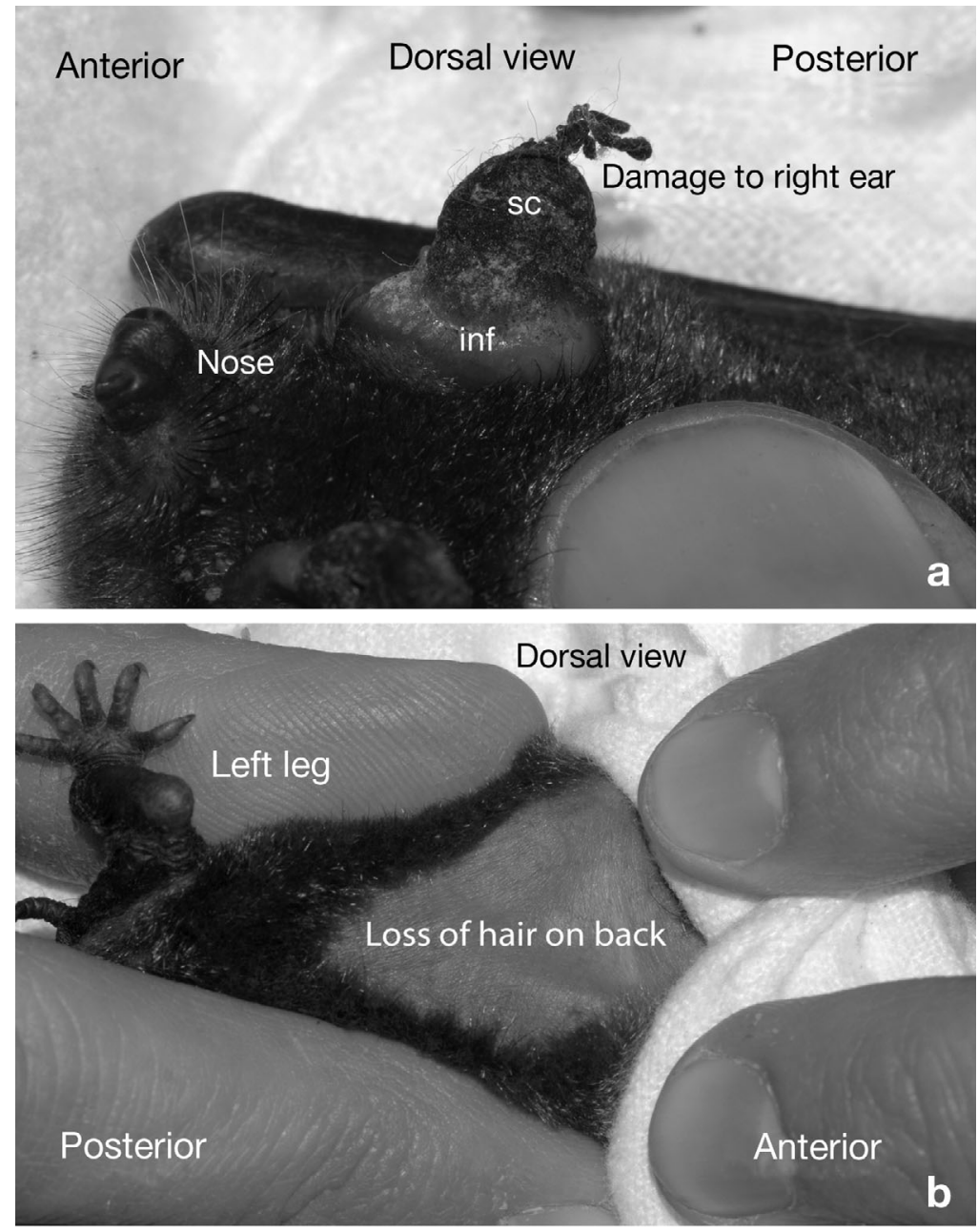

Fig. 1. Mystacina tuberculata. (a) Damage to the right ear and (b) balding on the back (the bat's head is covered by cloth) discovered on bats captured $232 \mathrm{~d}$ after release. Both photos were taken from above the dorsal surface of the bats. Note the scabbing (sc) on the distal end of the pinna and the inflammation (inf) of the exposed skin at its base in (a). Balding extended anteriorly as far as the nape of the neck. Photos by S. Parsons 
release. However, there was weak, non-statistical evidence that bats lost weight once supplementary feeding ceased, and all bats were returned to captivity because of a condition with an undiagnosed cause resulting in ear damage and balding.

The results of the present study contrast with those of the previous short-tailed bat translocation where bats either dispersed off the release island (B. D. Lloyd unpubl. data) or died soon after release. Results also contrast with other translocations and displacement homing experiments, where bats dispersed from their release sites (Davis 1966, Gunier \& Elder 1971, Guilbert et al. 2007, S. Swift pers. comm.). It is uncertain which of the release techniques (juvenile release, prerelease captivity and post-release supplementary resource provision) resulted in the different outcome, since they have been shown to independently contribute to decreased dispersal or increased survival elsewhere (e.g. Serventy et al. 1989, Bright \& Morris 1994, Armstrong \& Ewen 2001, Molony et al. 2006). Alternatively, factors unrelated to the release protocol, such as differences in release site quality, could also have been responsible for the different outcome. Regardless, our results show that using the NZDOC's new protocol, translocated bats can remain in the vicinity of their release site and survive initially after release.

Interestingly, the role of soft release (i.e. where an animal is moved to and maintained at the release site prior to release) in promoting site fidelity has recently been called into question. In macropods, experimental comparison of soft versus hard release protocols showed no significant effect on fidelity or survival (Hardman \& Moro 2006). In birds, soft releases may actually lower survivorship (e.g. Clarke et al. 2002). It may be useful for future research to investigate the relative importance of release method on the success of bat translocations.

The fate of the 11 bats not accounted for $232 \mathrm{~d}$ after release is unknown. Possibilities include bats remaining close to the release site but not returning to the immediate vicinity of the aviary, dispersal to remote parts of the island, attempted homing, death or any combination of these outcomes. Bats are small, volant and nocturnal, which makes determining the fate of all founders extremely difficult, even with the most intensive post-release monitoring. This problem is likely to occur in future translocations of bats.

There was no statistical evidence that bats decreased in weight over time; in fact, recaptured bats were a comparable in weight to Mystacina tuberculata from a natural population at the end of the study. However, there was weak, statistically non-significant evidence that they were lighter when supplementary feeding ceased than during irregular feeding. Meal- worms were consumed whenever provided (J. Ruffell unpubl. data), which may have reflected a reliance on supplementary food, or simply a preference for easily accessible resources (Armstrong \& Perrot 2000). Bats also sustained ear damage and balding during the no feeding regime, which may have contributed to the decrease in weight.

The lack of weight loss following release should be interpreted cautiously. Trends may have been difficult to detect because of our small sample size and because individual differences in weight were not accounted for. Furthermore, monitoring was cut short when bats were returned to captivity, the time when weights were most likely to decrease, as bats had ear damage, and balding and supplementary feeding had ceased. Continued monitoring may have provided stronger evidence that bats were decreasing in condition.

Regardless of whether bats lost weight, the translocation was unsuccessful because of the ear damage and balding that resulted in the NZDOC returning the bats to captivity. Because the cause could not be determined, it is uncertain if these symptoms would have affected the viability of the population had they been left untreated. Similarly, we do not know if ear damage and balding is likely to occur in future translocations. However, 2 aspects of the translocation may have predisposed the bats to disease. First, bats were captivereared and so may have been immunologically naïve to environmental pathogens (Viggers et al. 1993). Second, bats did not show normal roost-switching behaviour, which may have allowed a build-up of pathogens in the aviary. Bats roosted in the aviary on average every 1.8 d (J. Ruffell unpubl. data), whereas shorttailed bats in natural populations switch roosts regularly and leave roosts vacant for many months (Lloyd 2001), behaviours which may prevent a build-up of pathogens in the roost (Lewis 1995). Adjusting the translocation protocol to decrease the predisposition to disease may increase the likelihood of success of future translocations.

Although captive-rearing and aviary over-use predisposed bats to disease, other factors may also have caused the observed conditions. Kapiti Island may have had unusually high levels of the pathogen responsible. For example, a large number of hihi Notiomystis cincta translocated to Mokoia Island died from aspergillosis infection, despite supplementary feeding and the fact that the island was free from pestmammals. The island had higher levels of the aspergillosis spores than other islands where translocated hihi populations had remained healthy (Alley et al. 1999). Supplementary feeding may also have affected the bats' health. Mealworms are not the natural prey of bats and they are known to be relatively high in fat (Martin et al. 1976), but were the staple diet 
of the bats prior to release. However, the fact that the disease was detected after the cessation of supplementary feeding, and recurred long after it had stopped, suggests that this was not a causal factor.

Many species of bat require conservation management, and translocation could be a useful tool. The limited data on previous translocations of bats suggested that achieving success may be difficult, particularly due to dispersal from the release site. As such, the release protocol developed by the NZDOC was specifically tailored to reduce post-release dispersal and mortality. Our results demonstrate that under this protocol the initial elements of translocation success can be achieved - bats can be kept at their release site and survive initially following release. This protocol could serve as a starting model for the translocation of shorttailed and other species of bats.

Acknowledgements. We acknowledge the work of the large team of New Zealand Department of Conservation (NZDOC) staff who undertook the translocation, in particular L. Adams and B. Lloyd, who together conceived and led the project. We thank L. Adams, D. Wrightson and J. McIntosh from the NZDOC for their logistic support during work on Kapiti Island, and L. Adams and B. Lloyd for helpful comments on the manuscript. Work was funded by a grant and carried out under permit from the NZDOC.

\section{LITERATURE CITED}

Adams L, Wyeth J, Brady P, Lloyd B and others (2005) The capture and translocation of southern short-tailed bats (Mystacina tuberculata tuberculata) from Tararua Forest Park to the National Wildlife Centre, Mount Bruce, and transfer of juveniles to Kapiti Island. New Zealand Department of Conservation, Wellington

Alley MR, Castro I, Hunter JEB (1999) Aspergillosis in hihi (Notiomystis cincta) on Mokoia Island. N Z Vet J 47:88-91

Arkins AM, Winnington AP, Anderson S, Clout MN (1999) Diet and nectarivorous foraging behaviour of the shorttailed bat (Mystacina tuberculata). J Zool Lond 247: 183-187

Armstrong DP, Ewen JG (2001) Testing food limitation in reintroduced hihi populations: contrasting results for two islands. Pac Conserv Biol 7:87-92

Armstrong DP, Perrot JK (2000) An experiment testing whether condition and survival are limited by food supply in a reintroduced hihi population. Conserv Biol 14: 1171-1181

Bright PW, Morris PA (1994) Animal translocation for conservation: performance of dormice in relation to release methods, origin and season. J Appl Ecol 31:699-708

Campbell DJ (2002) Changes in numbers of woody plant seedlings on Kapiti Island after rat eradication. Science for Conservation 193. New Zealand Department of Conservation, Wellington

Clarke RH, Boulton RL, Clarke MF (2002) Translocation of the socially complex black-eared miner Manorina melantotis: a trial using hard and soft release techniques. Pac Conserv Biol 8:223-234

Davis R (1966) Homing performance and homing ability in bats. Ecol Monogr 36:201-237
Guilbert JM, Walker MM, Greif S, Parsons S (2007) Evidence of homing following translocation of long-tailed bats (Chalinolobus tuberculatus) at Grand Canyon Cave, New Zealand. N Z J Zool 34:239-246

Gummer H (2003) Chick translocation as a method of establishing new surface-nesting seabird colonies: a review. DOC Science Internal Series 150. New Zealand Department of Conservation, Wellington

Gunier WJ, Elder WH (1971) Experimental homing of gray bats to a maternity colony in a Missouri barn. Am Midl Nat 86:502-506

Hardman B, Moro D (2006) Optimising reintroduction success by delayed dispersal: Is release protocol important for hare-wallabies? Biol Conserv 128:403-411

IUCN (World Conservation Union) (1998) Guidelines for reintroductions. IUCN, Gland

IUCN (World Conservation Union) (2006) 2006 IUCN Red List of Threatened Species. Available at www.iucnredlist.org

Jones KE, Purvis A, Gittleman JL (2003) Biological correlates of extinction risk in bats. Am Nat 161:601-614

> Lewis SE (1995) Roost fidelity of bats: a review. J Mammal 76:481-496

Lloyd BD (2001) Advances in mammalogy 1990-2000: shorttailed bats. J R Soc N Z 31:59-81

Lloyd BD (2003a) The demographic history of the New Zealand short-tailed bat Mystacina tuberculata inferred from modified control region sequences. Mol Ecol 12: 1895-1911

Lloyd BD (2003b) Intraspecific phylogeny of the New Zealand short-tailed bat Mystacina tuberculata inferred from multiple mitochondrial gene sequences. Syst Biol 52:460-476

Lloyd BD (2005). Lesser short-tailed bat. In: King CM (ed) The handbook of New Zealand mammals. Oxford University Press, Auckland, p 59-66

> Martin RD, Rivers JPW, Cowgill UM (1976) Culturing mealworms as food for animals in captivity. Int Zoo Yearb 16: $63-70$

Mickleburgh SP, Hutson AM, Racey PA (eds) (1992). Old World fruit bats. An action plan for their conservation. IUCN/SSC Chiroptera Specialist Group, IUCN, Gland

Molloy J (1995) Bat (Peka peka) recovery plan. Threatened species recovery plan series. New Zealand Department of Conservation, Wellington

> Molony SE, Dowding CV, Baker PJ, Cuthill IC, Harris S (2006) The effect of translocation and temporary captivity on wildlife rehabilitation success: an experimental study using European hedgehogs (Erinaceus europaeus). Biol Conserv 130:530-537

Racey PA (1988) Reproductive assessment in bats. In: Kunz TH (ed) Ecological and behavioural methods for the study of bats. Smithsonian Institution Press, Washington, DC, p 31-43

Riskin DK, Parsons S, Schutt WA Jr, Carter GG, Hermanson JW (2006) Terrestrial locomotion of the New Zealand shorttailed bat Mystacina tuberculata and the common vampire bat Desmodus rotundus. J Exp Biol 209: 1725-1736

Ruffell J, Sedgeley J, Parsons S (2007) The potential availability of roosting sites for lesser short-tailed bats (Mystacina tuberculata) on Kapiti Island, New Zealand: implications for a translocation. N Z J Zool 34:219-226

Seddon PJ, Armstrong DP, Maloney RF (2007) Developing the science of reintroduction biology. Conserv Biol 21: 303-312

Sedgeley JA (2003) Roost site selection and roosting behaviour in lesser short-tailed bats (Mystacina tuberculata) in comparison with long-tailed bats (Chalinolobus tuberculatus) in Nothofagus forest, Fiordland. $N$ Z J Ecol 30: $227-241$ 
Sedgeley JA (2006) Roost site selection by lesser short-tailed bats (Mystacina tuberculata) in mixed podocarp-hardwood forest, Whenua Hou/Codfish Island, New Zealand. N Z J Zool 33:97-111

Serventy DL, Gunn BM, Skira IJ, Bradley JS, Wooler RD (1989) Fledgling translocation and philopatry in a seabird. Oecologia 81:428-429

Snit'ko VP (2007) Seasonal spatial differentiation of sex

Editorial responsibility: Stephen Rossiter,

London, UK groups in populations of resident bats species (Chiroptera, Vespertilionidae) in the southern Urals. Russ J Ecol 38: 334-368

Tomich PQ (1986) Mammals in Hawaii. Bishop Museum Press, Honolulu, HI

Viggers KL, Lindenmayer DB, Spratt DM (1993) The importance of disease in reintroduction programmes. Wildl Res 20:687-698

Submitted: August 7, 2008; Accepted: January 6, 2009

Proofs received from author(s): March 3, 2009 